\title{
Size-Related Differences in the Thermoregulatory Habits of Free-Ranging Komodo Dragons
}

\author{
Henry J. Harlow, ${ }^{1}$ Deni Purwandana, ${ }^{2}$ Tim S. Jessop, ${ }^{3}$ and John A. Phillips ${ }^{4}$ \\ ${ }^{1}$ Department of Zoology \& Physiology, University of Wyoming, Laramie, WY 82071, USA \\ ${ }^{2}$ Komodo Survival Program Indonesia, Jalan Pulau Moyo Komplek Karantina, Blok 4 No. 2 Denpasar, Bali 80222, Indonesia \\ ${ }^{3}$ Department of Zoology, University of Melbourne, Parkville 3010, Australia \\ ${ }^{4}$ Conservation and Research for Endangered Species, Zoological Society of San Diego, Escondido, CA 92027, USA
}

Correspondence should be addressed to Henry J. Harlow, hharlow@uwyo.edu

Received 11 January 2010; Accepted 14 June 2010

Academic Editor: Tobias Wang

Copyright ( $\odot 2010$ Henry J. Harlow et al. This is an open access article distributed under the Creative Commons Attribution License, which permits unrestricted use, distribution, and reproduction in any medium, provided the original work is properly cited.

\begin{abstract}
Thermoregulatory processes were compared among three-size groups of free-ranging Komodo dragons (Varanus komodoensis) comprising small (5-20 kg), medium (20-40 gm) and large (40-70 kg) lizards. While all size groups maintained a similar preferred body temperature of $\approx 35^{\circ} \mathrm{C}$, they achieved this end point differently. Small dragons appeared to engage in sun shuttling behavior more vigorously than large dragons as represented by their greater frequency of daily ambient temperature and light intensity changes as well as a greater activity and overall exposure to the sun. Large dragons were more sedentary and sun shuttled less. Further, they appear to rely to a greater extent on microhabitat selection and employed mouth gaping evaporative cooling to maintain their preferred operational temperature and prevent overheating. A potential ecological consequence of size-specific thermoregulatory habits for dragons is separation of foraging areas. In part, differences in thermoregulation could contribute to inducing shifts in predatory strategies from active foraging in small dragons to more sedentary sit-and-wait ambush predators in adults.
\end{abstract}

\section{Introduction}

During growth from hatchlings $(0.1 \mathrm{~kg})$ to adults (maximum of $87 \mathrm{~kg}$ ), Komodo dragons (Varanus komodoensis) express the entire range of adult body size distribution of the genus Varanus. Associated with these changes in body size during growth are shifts in an individual's ecology including habitat usage, predatory strategies, diet niche, and thermoregulatory behaviors [1-3]. For example, small juveniles are predominantly arboreal and forage on lizards, birds, and insects [4]. Medium-sized dragons are largely terrestrial and generalist predators, while larger dragons increasingly supplement their diet with ungulate prey including Timor deer (Cervus timorensis), wild pigs (Sus scrofa), and to some extent, water buffalo (Bubalus bubalis) $[1,3,4]$. Shifts in diet as a function of increasing body size result in altered feeding strategies moving from active foraging to a more sedentary sit-andwait predatory habit in larger lizards $[1,2,5]$. Concomitant activities necessitating behavioral thermoregulation are also integrated into daily movement patterns of Komodo dragons which may be size dependent. Terrestrial, diurnal lizards behaviorally regulate within a preferred body temperature $\left(T_{b}\right)$ range [6-9]. Measurements of the $T_{b}$ of lizards during daytime activity periods suggest that lizards have a single species-specific preferred $T_{b}[10,11]$ which would imply that the amplitude and duration of the preferred temperature is the same for all size groups. Indeed, we have found this to be true for Komodo dragons which express preferred temperature amplitude of about $35^{\circ} \mathrm{C}$ with a duration of around 5 hours regardless of body size [12]. However, in spite of this similarity in preferred temperature among size groups, the ontogenic transition in body size dictates that thermal/physical properties among lizards will differ, and as such, size-dependent thermoregulatory behavior are predicted to occur to achieve a similar body temperature endpoint. 


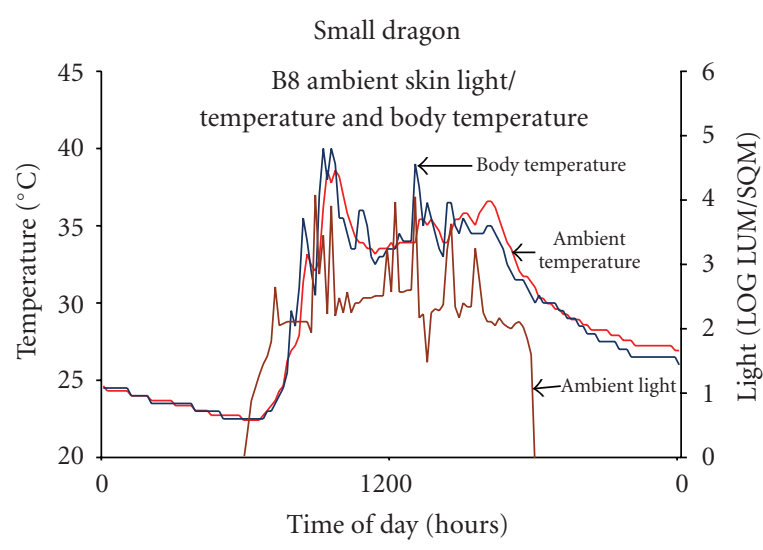

(a)

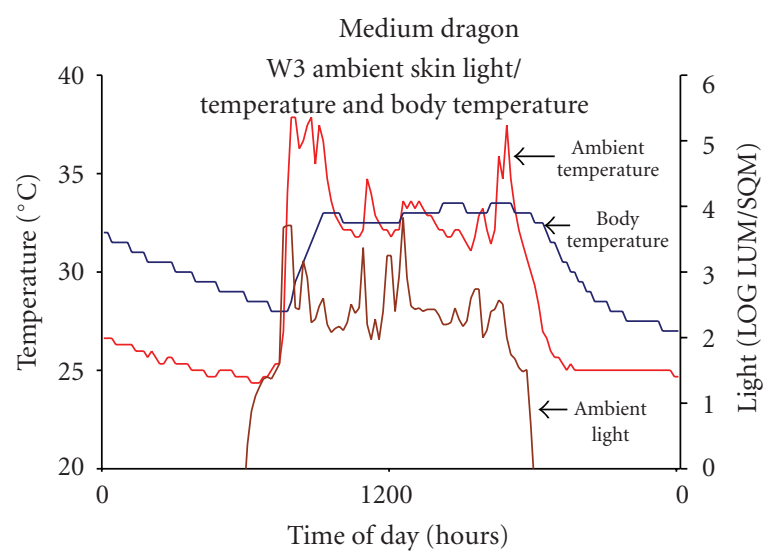

(b)

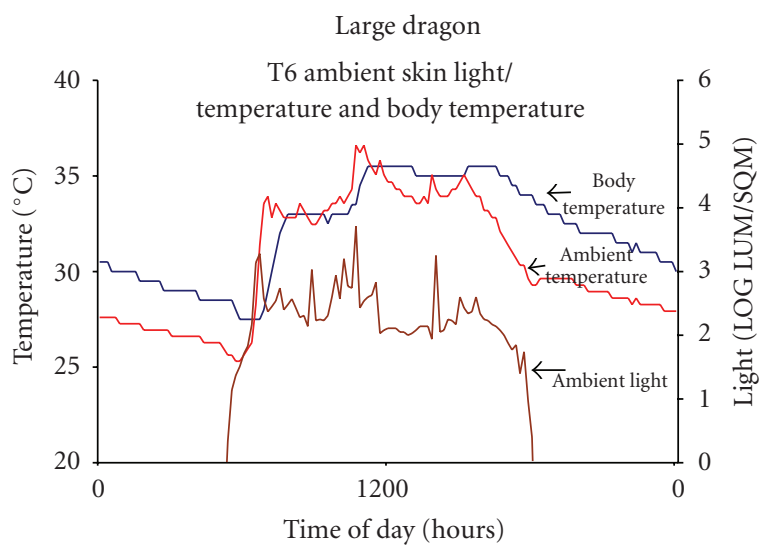

(c)

FIGURE 1: Daily body temperature and ambient light and temperature exposure by a representative (a) small $(5.6 \mathrm{~kg}$ ), (b) medium $(25 \mathrm{~kg})$, and (c) large $(70 \mathrm{~kg})$ Komodo dragon. Abrupt changes of over $0.5^{\circ} \mathrm{C}$ or $0.1 \log \mathrm{Lum} / \mathrm{m}^{2}$ represent temperature and light spikes, respectively.

It has been well established that body size influences the heat balance of ectothermic animals that thermoregulate through varying behavioral and physiological mechanisms that control $T_{b}$ [13-17]. For example, small ectothermic animals can heat and cool relatively quickly allowing them to take advantage of a changing thermal environment during

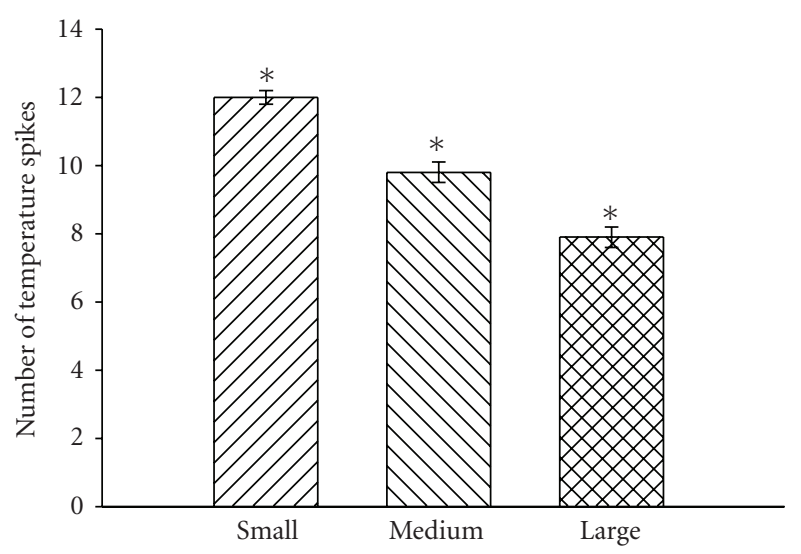

(a)

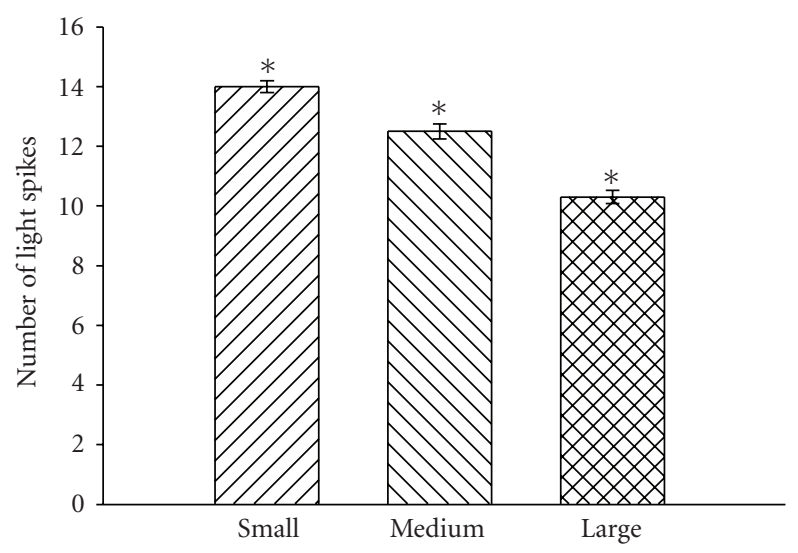

(b)

Figure 2: (a) Mean number of temperature spikes (abrupt $0.5^{\circ} \mathrm{C}$ changes) monitored by an OnSet temperature logger attached $4 \mathrm{~cm}$ above the skin of small $(n=6)$, medium $(n=6)$, and large $(n=6)$ dragons. (b) Mean number of light spikes (abrupt $0.1 \mathrm{log}$ Lum $/ \mathrm{m}^{2}$ changes) monitored by a light intensity logger attached $4 \mathrm{~cm}$ above the skin of small, medium, and large dragons. Vertical line represents \pm SEM. Asterisk depicts a significant difference between means at the $P<.05$ level.

their daily activity $[10,18-20]$ while large ectothermic animals would be unable to show similar patterns because of their long thermal time constant $[17,21,22]$. As pointed out by Brattstrom [6] on Australian varanids and suggested by Wikramanayake et al. [23] on Komodo dragons, the thermal inertia of large body size may influence their thermoregulatory behavior. Thus each dragon size group may be using selected microhabitats, have their own unique natural history and interact with their thermal environment differently. For example, small dragons are described by Auffenberg [2] as being active sun shuttlers, while medium-sized animals are thought to move less between sun and shade, and large dragons appear to become more sedentary throughout the afternoon. However, any shift in thermoregulatory behavior as a function of body mass, while suggested by Auffenberg [2] has not been adequately quantified on Komodo dragons in the field. In addition, Wikramanayake et al. [23] reported no difference in mean microhabitat selection by adult and 


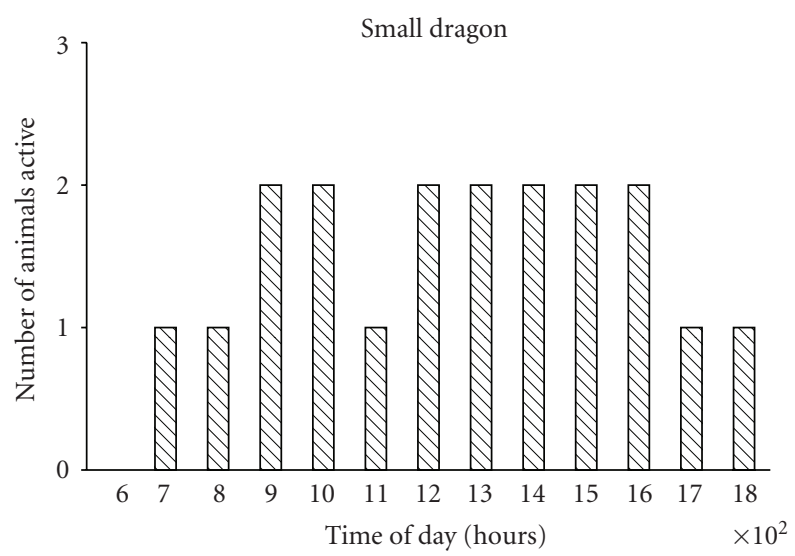

(a)

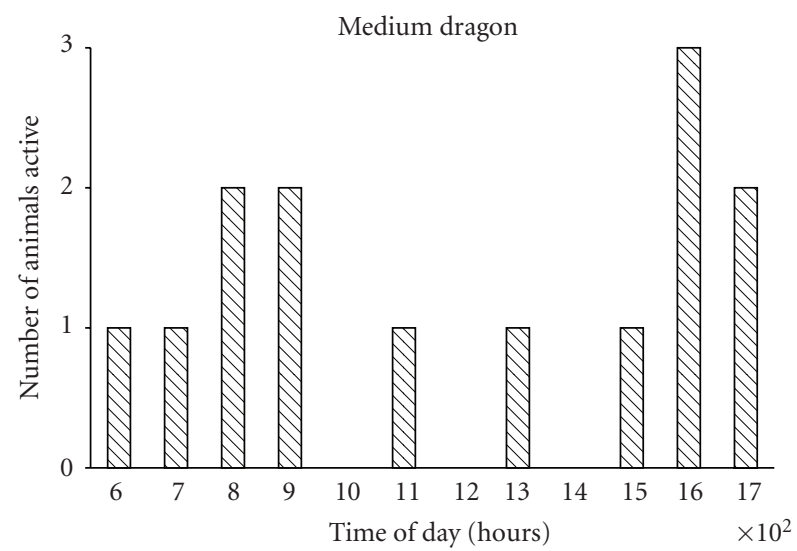

(b)

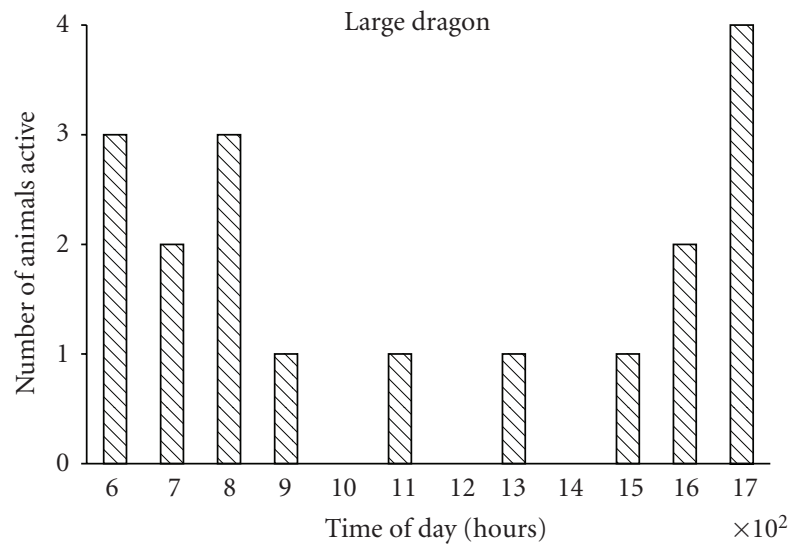

(c)

Figure 3: A representative hourly day-time census of small (a), medium (b), and large (c) dragons within the Loh Buaya ranger camp. Bars represent the number of animals within each size group that were observed active each hour between 0600 and 1700 .

juvenile Komodo Dragons as measured by temperature telemetry transmitters ingested by dragons (to give core body temperature) and transmitters attached to the skin (to provide microhabitat temperature $\left(T_{m}\right)$ ). They concluded that even though the juveniles may have a greater fluctuation in $T_{b}$, both the mean $T_{b}$ and $T_{m}$ were similar for these size

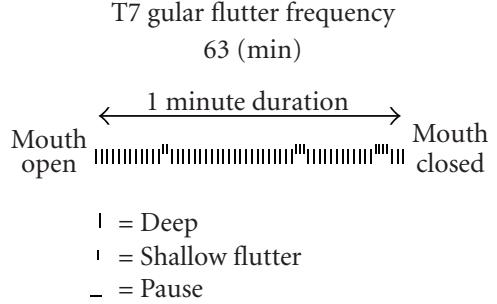

(a)

T3 gular flutter frequency $42(\min )$

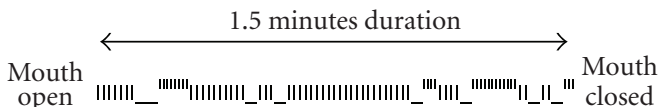

1 = Deep

1 = Shallow flutter

_ = Pause

(b)

$$
\begin{aligned}
& \text { T2 gular flutter frequency } \\
& 68 \text { (min) }
\end{aligned}
$$

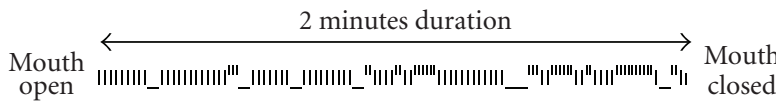

$$
\begin{aligned}
& 1 \text { = Deep } \\
& \text { I = Shallow flutter } \\
& \text { _ }=\text { Pause }
\end{aligned}
$$

FIGURE 4: Three representative profiles of observed gular movement by large dragons during the heat of the day. The long vertical bar represents a deep flutter; short bars are shallow flutter and horizontal bars indicate no flutter movements. The horizontal arrow depicts the duration of a gular flutter bout.

classes of dragons and conclude that they are using the same microhabitat.

However, energy budget theory [24-26] predicts that the rapid response time to temperature fluctuations by smallsized dragons should result in their enhanced exploitation of a thermally heterogeneous environment encountered during active sun shuttling and foraging for small prey. On the other hand, larger dragons with greater thermal inertia and employing sit-and-wait ambush capture of bigger prey species should have reduced daily activity bouts and sun shuttling. To achieve a similar preferred body temperature as smaller dragons [12], large animals may require a greater expression of physiological processes such as metabolic heat production [27] to gain heat in the morning or evaporative cooling to avoid overheating during the hot afternoon hours. While some large reptiles $(250-430 \mathrm{~kg}$ ) have higher than predicted resting metabolic rates which may result in a core to skin temperature difference of $20^{\circ} \mathrm{C}$, the metabolic heat retention is not as profound in reptiles less than $100 \mathrm{~kg}$ [28] typical of Komodo dragons in this study. However, mouth gaping [29], gular pumping (high-amplitude movements), and gular fluttering (high-frequency movements) have been 


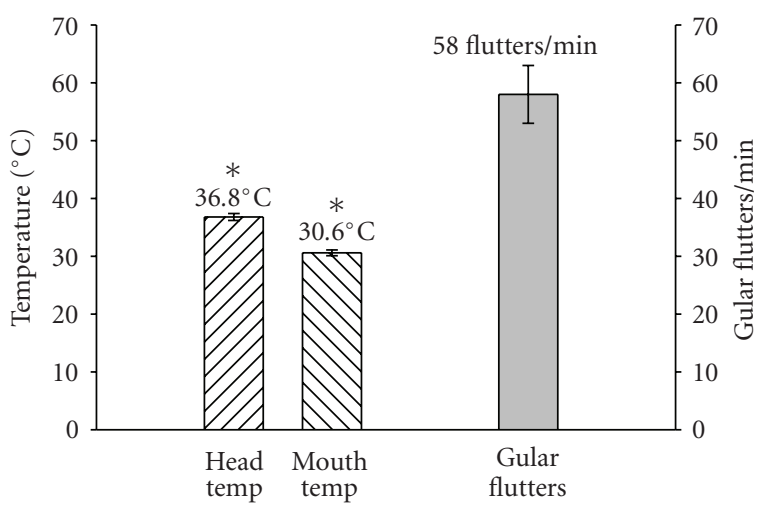

Figure 5: Mean temperature $\left({ }^{\circ} \mathrm{C}\right)$ of the mouth and head/neck of 5 large Komodo dragons during bouts of gular fluttering. The grey bar depicts the mean number of gular flutters during an individual bout. Vertical line represents SEM. Asterisk depicts a significant difference between means at the $P<.05$ level.

described for varanids and other reptiles [30-32] with the process thought to aid in evaporative cooling by increasing convective heat loss $[33,34]$. This heat loss is associated with a difference of temperature between head and body [35] the magnitude of which increases with body size [29].

Hypothesis tested in this study are $\mathrm{H}_{1}$ : smaller dragons sun shuttle to a greater extent than larger dragons to achieve their preferred $T_{b} ; \mathrm{H}_{2}$ : smaller dragons are active throughout the day; $\mathrm{H}_{3}$ : larger dragons are more sedentary sit-and-wait predators that use physiological mechanisms to regulate their body temperature while exposed to mid afternoon highambient temperatures. Specific objectives of this study are to (1) quantify activity and sun shuttling behavior as it relates to the maintenance of a preferred body temperature by small, medium, and large free-ranging Komodo dragons, (2) investigate mouth gaping and evaporative cooling by different size groups of dragons throughout the day and night, and (3) interpret how interactions among body size and thermoregulation could influence other key aspects of this lizard's ecology such as size-related foraging habits.

\section{Materials and Methods}

2.1. Study Area. Free-ranging Komodo dragons were investigated within a $500 \mathrm{sq} \mathrm{km}$ study area within Loh Buaya Valley $\left(8^{\circ} 39^{\prime} \mathrm{S}\right.$; $\left.119^{\circ} 43^{\prime} \mathrm{W}\right)$ on Rinca island within Komodo National Park, Indonesia during the late dry season (October/November).

The habitat types within this valley comprise four distinct vegetation classes: (1) deciduous monsoon forest (providing a mosaic of light and shade), (2) savannah grassland/woodland (open hot grassland with intermittent shade trees), (3) mangrove forest (closed canopy), and (4) riparian evergreen forest. These habitat types transition abruptly across ecotones and provide thermal environments that range from near full sun (e.g., Savannah grassland) to near full shade (e.g., Mangrove forest). While Komodo dragons can be found to use all habitat types, they typically prefer the deciduous monsoon forest [2].

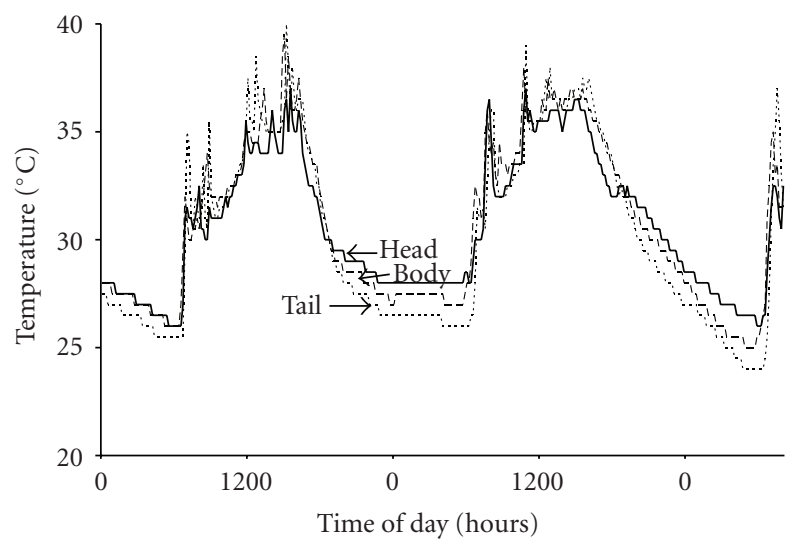

Figure 6: Profile of a representative Komodo dragon with ibutton loggers recording the skin temperature of the head, body, and tail over a two-day duration.

2.2. Animal Capture and Monitoring. Dragons ranging from $5-70 \mathrm{~kg}$ were captured in $0.5 \times 0.5 \times 3 \mathrm{~m}$ aluminum traps with a sliding door that dropped when dragons pulled a release pin attached to bait within the trap. In addition, many dragons of all body sizes were hand captured by overpowering the animal with the aid of several skilled Park rangers. Monitored animals were categorized and subsequently analyzed as three size groups consisting of small (5-20 kg), medium (20-40 kg), and large ( $>40 \mathrm{~kg}$ ) dragons.

VHF tracking transmitters (ATS Inc., North Isanti, Minnesota USA model M1235; diameter $5.5 \mathrm{~cm} \times 11.2 \mathrm{~cm}$ length, and $650 \mathrm{gm}$ weight) were placed on the hip of six large dragons with nylon straps that went around their body and crossed their hind limbs. Custom built ATS transmitters (weight $=200 \mathrm{gm}$ ) were placed on six mediumsized dragons. ATS Model M1235 (diameter $1.8 \mathrm{~cm} \times 7.9 \mathrm{~cm}$ length, 24 grams weight) transmitters were placed on six smaller dragons ( 5 to $20 \mathrm{~kg}$ ).

StowAway Tidbit temperature loggers $\left(0.2^{\circ} \mathrm{C}\right.$ accuracy; Onset, Procasset, Massachusetts, USA) were attached to the top of the VHF tracking transmitters to record ambient temperatures $\left(T_{a}\right)$ around the free-ranging dragons without having contact with the skin. StowAway, model LI light intensity loggers (Onset, Procasset, Massachusetts, USA) were also attached to the top of the VHF tracking transmitters for monitoring ambient light intensity as dragons moved freely through their environment. Deep core body temperature $\left(T_{b}\right)$ of dragons in each body mass group was measured with an iButton temperature logger (Model DS 1921; Maxim, Dallas Semiconductor Inc., Dallas, USA). These loggers were epoxy glued to ATS model M1235 telemetry transmitters (cylindrical with dimensions, $1.8 \mathrm{~cm}$ diameter $\times 7.9 \mathrm{~cm}$ length, $24 \mathrm{gm}$ weight with extended range). The telemetry transmitter and attached iButton temperature logger were placed within a piece of meat and fed to dragons. iButton loggers were also epoxy glued to the top of the head, mid length on the body, and top of the tail on four large dragons. Body surface loggers were programmed to record temperatures and light intensities every 5 minutes while 
core body temperature loggers recorded every 20 minutes. Once the signal from the internal VHF transmitter did not coincide with the external tracking transmitter on the dragon, we assumed it had been defecated. The transmitter with attached iButton were retrieved then data downloaded into a laptop computer with interpretative software (Maxim, Dallas Semiconductor Inc., Dallas, USA) for analysis of daily internal body temperature profiles over the duration of time the logger and transmitter were in the gastrointestinal track of the dragon (2-5 days). The VHF tracking transmitter, ambient and body surface temperature loggers, and light intensity loggers were retrieved from dragons at night while the animals were sleeping. Data from the ambient temperature and light intensity loggers were downloaded into a BoxCar Pro 4.0 software program for interpretation (OnSet, Pocasset, Massachusetts, USA) and body surface temperature via Maxim software (Dallas Semiconductor Inc., Dallas, USA). As dragons moved about freely from areas of sun and shade, spikes in both ambient light intensity and ambient temperature were recorded by the loggers. A spike in light was defined as an abrupt increase in intensity $>0.1 \mathrm{log}$ Lux/square meter and a spike in ambient temperature as an abrupt temperature increase $>0.5^{\circ} \mathrm{C}$ over a 5 minute interval as the dragons moved through their thermal environment. The number of ambient light and temperature spikes during a day recording was counted and compared among small, medium, and large dragons as indicators of movement patterns and sun light shuttling.

A survey of daily activity by dragons that were found within the Lou Buaya ranger camp and adjoining area (approximately $3 \mathrm{~km}^{2}$ ) was conducted on three occasions between 0600-1700. During this time, the observer would walk through the study area every hour to record each dragon (1) as to its size group, (2) if active or at rest, and (3) if in the sun or shade. Each day's profile was plotted and the overall percent of animals found active/rest and in the sun/shade was calculated for the size groups.

Notations were made on the size group of dragons that were observed in the field engaging in mouth gaping and gular movement through the course of this study. When encountered, the number and pattern of gular movements were recorded. This behavior had a discrete start and stop interval that was timed with a stop watch. The temperature within the mouth and along the back of the neck/head was also obtained during this interval by aiming the beam of an Raytek Ranger model RAYMXAPU infrared temperature sensor (Raytek Corp. Santa Cruz Calif. USA) at the target area from a distance of approximately $1.5 \mathrm{~m}$. This method is similar to that used by Tattersall et al. [30] who measured tongue temperatures of reptiles. All animal handling procedures and experimental design were approved by Komodo National Park authorities and the animal welfare committee of the Zoological Society of San Diego.

Analysis of variance (ANOVA) and posthoc Tukey test for pair-wise comparison was conducted to assess differences in the number of day-time light and temperature spikes for six small, medium, and large dragons. ANOVA and posthoc Tukey test were also conducted on mean head, body, and tail temperatures of four large dragons. A students $t$-test was used for comparing head and mouth temperatures of five dragons [36].

\section{Results}

Figures 1(a)-1(c) display daily ambient temperature and light intensities as well as core body temperature experienced by a representative small- $(5.6 \mathrm{~kg})$, medium- $(25 \mathrm{~kg})$, and large- $(70 \mathrm{~kg})$ sized dragons. With the criteria previously described, there was a significant difference $(P<.05)$ in the number of temperature spikes between size groups with a mean of $12( \pm 0.2$ SEM) for small dragons $(n=6)$, compared to $9.8( \pm 0.25$ SEM $)$ and $7.9( \pm 0.22$ SEM $)$ for medium $(n=6)$ and large $(n=6)$ dragons, respectively (Figure 2(a)). Similarly, significant differences $(P<.05)$ were found for the number of ambient light spikes with a mean of $14( \pm 0.15$ SEM) per day for the small compared to 12.5 $( \pm 0.16$ SEM) and $10.3( \pm 0.13$ SEM $)$ for the medium and large dragon groups, respectively (Figure 2(b)). Much like the number of light and temperature spikes, small dragons also appeared to exhibit a greater amount of overall daily activity. Figures 3(a)-3(c) depict a representative daily profile of the number of observed active small, medium, and large dragons between 0600-1700 within the Loh Buaya ranger camp area. These examples are typical of other observation days where the number of active small dragons is fairly constant throughout the survey period while the number of medium and large dragons tends to become more bimodal with less activity during midday high-ambient temperature. Over the total observation days, the percent animal's active during the survey period was 79\%, 39\%, and 35\% for small, medium, and large dragons, respectively. Accordingly, the percent of animals recorded to be in the sun during the survey period was $43 \%, 28 \%$, and $18 \%$ for small, medium, and large dragons, respectively.

Of all the size groups observed in this study, only dragons above $40 \mathrm{~kg}$ exhibited mouth gaping and gular flutter behaviors and they occurred during the warmest periods of the afternoon (1200-1600). As represented in Figures 4(a)$4(\mathrm{c})$, these episodes were characterized by irregular intervals of deep and shallow gular extensions often interspersed by momentary pauses. The entire episodes were less than two minutes in duration. Between these bouts, dragons would close their mouth for $0.5-2$ minutes before reopening it revealing copious amounts of saliva stringing from the upper jaw and teeth. There was a significant difference $(P<.05)$ between the head and mouth temperatures of five large dragons (Figure 5$)$. An average of 58 ( \pm 6.0 SEM) flutters per minute $(n=5)$ was associated with a difference of $6.2^{\circ} \mathrm{C}$ between inside mouth temperature and outside head/neck temperatures (Figure 5).

As shown in a representative large-sized $(40 \mathrm{~kg})$ dragon (Figure 6), surface head, body, and tail temperatures were similar during heating and while within their preferred body temperature activity range, however, the head temperature remained higher than body and tail temperature during cooling at night. Of the four animals reported, the head was significantly warmer $(P<.05)$ than the body and tail $\left(1.0^{\circ} \mathrm{C}\right.$ 
$( \pm 0.35)$ and $\left.2.2^{\circ} \mathrm{C}( \pm 0.21)\right)$, respectively, for a period of 5.2 $( \pm 0.70)$ hours during the night and early morning.

\section{Discussion}

Komodo dragons that span 4 orders of magnitude in size during ontogenic growth are mobile with large home ranges by reptilian standards that encompass many types of microhabitats [4, 37]. While moving within these areas there are at least two interdependent influences on their thermoregulatory biology. The first is related to transitional foraging and predatory behavior as dragons increase in size. Small dragons feed on insects, reptiles, rodents, and birds (and eggs) that are either on the ground or in trees while medium-sized animals $(<40 \mathrm{~kg})$ ingest large prey such as nesting birds and juvenile ungulates, and they feed on carrion but, larger dragons in excess of $40 \mathrm{~kg}$ are increasingly sedentary sit-and-wait ambush predators targeting ungulate prey [2]. The second influence on thermoregulation of Komodo dragons is the physical relationship of heat transfer as the surface-to-volume ratio decreases with increased body size. In a companion study [12], and also expressed in this paper, we found that dragons regulate a relatively tight preferred $T_{b}$ plateau in their natural environment and have an overall mean $T_{b}$ of about $35^{\circ} \mathrm{C}$ with a duration of approximately 5 hours which is expressed by all size groups. Here we report that the manner in which this preferred $T_{b}$ plateau is achieved has size-dependent thermoregulatory characteristics that potentially influence a lizards' capacity for daily movement within the thermal environment.

It has been proposed [23] that because of the large mass difference between juvenile and adult Komodo dragons, body temperature regulation of these size groups should differ, reflecting unique microhabitat use patterns and behaviors. However, when Wikramanayake et al. [23] calculated mean microhabitat temperatures $\left(T_{m}\right)$ of free-ranging Komodo dragons, they found that $T_{m} \mathrm{~s}$ were similar $\left(35.4^{\circ} \mathrm{C}\right.$ versus $36^{\circ} \mathrm{C}$ ) for juveniles and adults, suggesting that they use the same microclimate profiles for thermoregulation. But, these authors also state that because of their smaller body mass, juveniles may lose heat more rapidly than adults in the cooler microhabitats and when they are exposed to more extreme $T_{a}$ fluctuations than adults. In a complimentary study [12], we found that small dragons do heat and cool faster than large dragons and there is a mass-dependent linear relationship with a lower cooling constant and highthermal conductivity for larger dragons. We also found small dragons to have a greater amplitude between daily minimum and maximum $T_{b}$ than larger dragons [12]. However, unlike the conclusions made by Wikramanayake et al. [23] our data compels us to support the claim that there is a distinct difference in the daily profile of microclimates experienced by the three size groups of free-ranging dragons and this reflects profound differences in their thermoregulatory behavior. We used several indices in concert to measure the extent by which Komodo dragons make size-related thermoregulatory adjustments. Light and temperature loggers attached to freeranging dragons in our study measured transient ambient conditions experienced by dragons. As such, we identified smaller dragons to move from areas with warm ambient temperatures and exposed sunlight to areas of cooler ambient temperatures and shade a significantly greater number of times each day than medium and large dragons to achieve their preferred $T_{b}$. These data thereby indicate a sizedependent difference in microhabitat use pattern by dragons. We feel the study by Wikramanayake et al. [23] may not have identified the acuteness of these ambient differences because their measurement of microhabitat temperature was based upon a temperature transmitter directly attached to the skin and not elevated from the surface of the body as in our study. Their arrangement may have reduced the capacity for measuring rapidly changing ambient temperature readings due to the thermal inertia of skin temperature associated with the dragon's body mass. In addition, Wikramanayake et al. [23] did not measure light intensity as an associated parameter indicative of sun shuttling behavior as in the present study. A third index that we employed for evaluating thermal adjustments by Komodo dragons was based upon observations $[15,16]$ that the frequency of movement, the percentage of time in sun and shade as well as proportion of the population in the sun, serve as measurements of shuttling behavior and extent of basking intensity. From the accumulative daily observations made while surveying dragons in the Loh Buaya camp (at $1 \mathrm{hr}$ intervals between 0700-1700), small dragons were observed $79 \%$ of the time to be active compared to only $35 \%$ by large dragons and small dragons were found exposed to the direct sunlight for $43 \%$ of these observations compared to only $18 \%$ by large dragons. Daily activity profiles of small dragons also suggest almost continuous diurnal movement as compared to a distinct trend for medium and larger dragons to be less active during the mid-afternoon periods. These data, in concert with daily peaks in light and heat exposure, support our claim that size does influence microhabitat selection and that smaller dragons are using sun shuttling more effectively than the larger dragons. Indeed, small dragons can heat and cool relatively quickly [12], thereby taking advantage of short intervals of time when portions of a thermally heterogeneous mosaic environment can be exploited by employing relatively rapid sun shuttling to maintain a preferred $T_{b}$ as demonstrated in other smaller lizard species [10, 18-20].

Thermal inertia may be playing a distinct role here because medium-sized dragons appear to be in a transition between effective sun shuttling and more sedentary basking in their achievement of an identical preferred $T_{b}$ as the smaller dragons. Large ectotherms would be unable to show sun shuttling patterns because of their long thermal time constant $[21,22,38]$ and must employ other thermoregulatory mechanisms. This fits well into the framework of predatory strategies by Komodo dragons. Small dragons engage in continuous foraging behavior for lizards, insects, and small mammals. Increased mass of dragons, with greater thermal inertia and reduced sun shuttling effectiveness, in part, could necessitate the transition to ambush sit-and-wait predation particularly during the hot afternoon where the largest dragons capable of attacking the biggest prey exhibit almost 
no sun shuttling behaviors. Hence while reptiles exhibit transitions in foraging mode for multiple reasons [39] the advent of sit-and-wait predating in large Komodo dragons, is in part, intuitively associated with the biophysical properties of large body size and the need for specific thermoregulatory behaviors [40]. Indeed, large dragons do achieve and maintain a preferred $T_{b}$ similar in amplitude and duration as smaller individuals [12]. Consequently, large dragons that do not sun shuttle to thermoregulate and are more sedentary must use a combination of selecting a microhabitat for conductive/convective heat transfer [12] in concert with active physiological mechanisms as described by Crawford [41]. Many reptiles use open mouth evaporative water loss from the oral mucosa to cool blood in the carotid arteries that run very close to the surface of the mouth thereby reducing head and, potentially, body temperature during exposure to a hot environment [35]. In our study, Komodo dragons did not appear to pant which is defined as increased breathing frequency with decreased tidal volume $[42,43]$. This is in agreement with conclusions made by Auffenberg [2]. However, as also observed by Auffenberg [2], we found that dragons express open mouth gaping facilitated by gular pumping which aids in evaporative cooling in other reptiles [32-34, 44, 45]. This pattern was not continuous for Komodo dragons, but appeared to be an irregular expression of high- and lowamplitude gular pumping movements interspersed by pauses of varying length between 2-5 seconds which is similar to other reptiles $[30,46]$. Episodes of open mouth gaping and gular movements were generally around 1-2 minutes in duration with an average gular frequency of 58 movements per minute as documented in other varanid species [31].

By measuring the oral cavity temperature with a remote infrared sensor, we found this area to be $6.2^{\circ} \mathrm{C}$ below that of the skin temperature on the head and neck region. Interestingly, we noted this behavior only in larger Komodo dragons $(>40 \mathrm{~kg}$ ) and during the hottest portion of the afternoon when they were sedentary. Size dependent mouth gaping has been reported in the alligator with increased expression by larger individuals $[25,29]$. In large Komodo dragons, these events coincided with that of their preferred $T_{b}$ plateau suggesting that it may be a method for fine tuning their body temperature regulation [33, 35, 47]. Indeed, big Komodo dragons may use mouth gaping as an inexpensive way to thermoregulate without moving about to sun shuttle [48] as employed by the smaller dragons. While we do not suggest that smaller dragons are incapable of expressing this behavior, our data does imply that larger dragons display it more readily as a thermoregulatory mechanism.

Evaporative water loss with a concomitant reduction in mouth temperature has been credited with producing a differential head and body temperature in numerous taxa [31, 33, 41, 49-55]. However, we did not see a difference in the skin temperature of the head, body, and tail using the iButton loggers during morning heating and afternoon thermoregulating periods of large dragons which were characteristically used upon mouth gaping while within the preferred $T_{b}$ plateau. The lack of regional differences in temperature suggests that if blood is being cooled by buccal evaporation it is not being localized in the head region but is dispersed throughout the entire circulatory system to help guard against whole body overheating. But, how does this explain a warmer head temperature compared to the body and tail as dragons cool during night time and early morning hours? It may be that heat conducted from the substrate is dissipated slowly during the night. Komodo dragons have a very thick skull [2] with bone having a high-conductivity coefficient $(0.53 \mathrm{~W} / \mathrm{mK}$; [56]) compared to tissue $(0.3 \mathrm{~W} / \mathrm{mK}$; [57]). Therefore, the head could gain more heat from the warmer night time substrate. Indeed, some nocturnal reptiles keep their head close to the ground during the night in order to maximize heat transfer to the head region [58]. We have observed that sleeping dragons select a pose during the night with their heads pressed closely to the substrate which generally is several degrees higher than the immediate air temperature above the ground. A counter current heat exchange system may be operating as described in other lizard species [59] to retard the rate of heat loss in the head region. The potential advantage of a warmer brain would be to facilitate a fight-or-flight response at night and enhance an early onset to activity during the morning when the body temperature is at its lowest.

It is often viewed that behavior performed for the purpose of $T_{b}$ regulation is a cost $[15,17,60-62]$ if the animal cannot expend effort during this interval of basking and sun shuttling to perform other behaviors such as foraging. We observed that the almost continuous day time movement of smaller dragons was often associated with prey capture as was the sit-and-wait ambush behavior of more sedentary larger dragons. In an associated study (Phillips and Harlow in preparation), we found that running velocity by dragons has a $\mathrm{Q}_{10} \approx 1.0$ and is temperature independent. As a result, dragons can be effective predators during a period of active thermoregulation such as morning hours of sun shuttling and basking. Because prey acquisition and body temperate regulation appear to overlap by dragons in our study area, this would reduce the cost expenditure for achieving a relatively constant $T_{b}$ that maximizes cellular performance equally in all size groups of these dragons.

\section{Acknowledgments}

Special thanks are given to Claudio Ciofi for use of telemetry equipment, advice, and assistance in the field. Appreciation is extended to Jeri Imansyah and to all of the Komodo National Park rangers on Rinca for their hospitality, hard work, and enthusiastic participation on this project which was a collaborative effort between Komodo National Park and the Zoological Society of San Diego. Financial support for this study was provided by the Zoological Society of San Diego and the Offield Family Foundation.

\section{References}

[1] W. Auffenberg, "Social and feeding behavior in Varanus komodensis," in Behavior and Neurology of Lizards, N. Greenberg and P.C. MacLean, Eds., pp. 301-331, NIMH, Rockville, Md, USA, 1978.

[2] W. Auffenberg, The Behavioral Ecology of the Komodo Monitor, University of Florida Press, Gainesville, Fla, USA, 1981. 
[3] T. S. Jessop, T. Madsen, J. Sumner, H. Rudiharto, J. A. Phillips, and C. Ciofi, "Maximum body size among insular Komodo dragon populations covaries with large prey density," Oikos, vol. 112, no. 2, pp. 422-429, 2006.

[4] M. J. Imansyah, T. S. Jessop, C. Ciofi, and Z. Akbar, "Ontogenetic differences in the spatial ecology of immature Komodo dragons," Journal of Zoology, vol. 274, no. 2, pp. 107$115,2008$.

[5] C. Ciofi and M. W. Bruford, "Genetic structure and gene flow among Komodo dragon populations inferred by microsatellite loci analysis," Molecular Ecology, vol. 8, no. 12, pp. S17-S30, 1999.

[6] B. J. Brattstrom, "Body temperatures of reptiles," American Midland Naturalist, vol. 73, pp. 376-422, 1965.

[7] J. A. Diaz, "Field thermoregulatory behavior in the western canarian lizard Gallotia galloti," Journal of Herpetology, vol. 28, no. 3, pp. 325-333, 1994.

[8] K. A. Christian and B. W. Weavers, "Thermoregulation of monitor lizards in australia: An evaluation of methods in thermal biology," Ecological Monographs, vol. 66, no. 2, pp. 139-157, 1996.

[9] G. Tosini and R. Avery, "Spectral composition of light influences thermoregulatory behaviour in a lacertid lizard (Podarcis muralis)," Journal of Thermal Biology, vol. 21, no. 3, pp. 191-195, 1996.

[10] R. B. Cowles and C. M. Bogert, "A preliminary study of the thermal requirements of desert reptiles," Bulletin American Museum Natural History, vol. 83, pp. 261-296, 1944.

[11] J. R. Templeton, "Reptiles," in Comparative Physiology of Thermoregulation, G. C. Whittow, Ed., vol. 1, pp. 167-331, Academic Press, New York, NY, USA, 1970.

[12] H. J. Harlow, D. Purwandana, T. S. Jessop, and J. A. Phillips, "Body temperature and thermoregulation of Komodo dragons in the field," Journal of Thermal Biology, In press.

[13] B. Heinrich, "Ecological and evolutionary perspectives," in Insect Thermoregulation, E. Heinrich, Ed., pp. 235-302, John Wiley \& Sons, New York, NY, USA, 1981.

[14] G. A. Bartholomew, "Physiological control of body temperature," in Biology of the Reptilian, C. Gans and F. H. Pough, Eds., vol. 12 of Physiological Ecology, Physiology C., pp. 167211, Academic Press, New York, NY, USA, 1982.

[15] R. B. Huey, "Physiological consequences of habitat selectio," American Naturalist, vol. 137, no. S91, p. S115, 1982.

[16] R. B. Huey and R. D. Stevenson, "Integrating thermal physiology and ecology of ectotherms: a discussion of approaches," WAmerican Zoologist, vol. 19, pp. 357-366, 1979.

[17] F. Seebacher, "Behavioural postures and the rate of body temperature change in wild freshwater crocodiles, Crocodylus johnstoni," Physiological and Biochemical Zoology, vol. 72, no. 1, pp. 57-63, 1999.

[18] G. C. Grigg, C. R. Drane, and G. P. Courtice, "Time constants of heating and cooling in the eastern water dragon, Physignathus lesueruii and some generalizations about heating and cooling in reptiles," Journal of Thermal Biology, vol. 4, no. 1, pp. 95-103, 1979.

[19] S. L. Robertson and E. N. Smith, "Thermal conductance and its relation to thermal time constants," Journal of Thermal Biology, vol. 6, no. 3, pp. 129-143, 1981.

[20] J. A. Díaz, "Ecological correlates of the thermal quality of an ectotherm's habitat: a comparison between two temperate lizard populations," Functional Ecology, vol. 11, no. 1, pp. 7989, 1997.

[21] R. D. Stevenson, "The relative importance of behavioral and physiological adjustments controlling body temperature in terrestrial ectotherms," American Naturalist, vol. 126, no. 3, pp. 362-386, 1985.

[22] G. C. Grigg, F. Seebacher, L. A. Beard, and D. Morris, "Thermal relations of large crocodiles, Crocodylus porosus, free-ranging in a naturalistic situation," Proceedings of the Royal Society of London B, vol. 265, no. 1407, pp. 1793-1799, 1998.

[23] E. D. Wikramanayake, W. Ridwan, and D. Marcellini, "The thermal ecology of free-ranging komodo dragons, Varanus komodoensis, on Komodo Island, Indonesia," in Advances in Monitor Research II, H.-G. Horn and W. Bohme, Eds., Mertensiella, Rheinbach, Germany, 1999.

[24] D. M. Gates, Energy Exchange in the Biosphere, Harper and Row, New York, NY, USA, 1962.

[25] J. R. Spotila, O. H. Soule, and D. M. Gates, "The biophysical ecology of the alligator: heat energy budgets and climate spaces," Ecology, vol. 53, pp. 1094-1102, 1972.

[26] K. A. Christian, C. R. Tracy, and C. R. Tracy, "Evaluating thermoregulation in reptiles: an appropriate null model," American Naturalist, vol. 168, no. 3, pp. 421-430, 2006.

[27] B. P. Wallace and T. T. Jones, "What makes marine turtles go: a review of metabolic rates and their consequences," Journal of Experimental Marine Biology and Ecology, vol. 356, no. 1-2, pp. 8-24, 2008.

[28] F. V. Paladino, M. P. O’Connor, and J. R. Spotila, "Metabolism of leatherback turtles, gigantothermy, and thermoregulation of dinosaurs," Nature, vol. 344, no. 6269, pp. 858-860, 1990.

[29] J. R. Spotila, K. M. Terpin, and P. Dodson, "Mouth gaping as an effective thermoregulatory device in alligators," Nature, vol. 265, no. 5591, pp. 235-236, 1977.

[30] G. J. Tattersall, V. Cadena, and M. C. Skinner, "Respiratory cooling and thermoregulatory coupling in reptiles," Respiratory Physiology and Neurobiology, vol. 154, no. 1-2, pp. 302318, 2006.

[31] C. R. Johnson, "Head-body temperature differences in Varanus gouldii (Sauria: Varanidae)," Comparative Biochemistry and Physiology_Part A, vol. 43, no. 4, pp. 1025-1029, 1972.

[32] G. A. Bartholomew and V. A. Tucker, "Size, body temperature, thermal conductance, oxygen consumption, and heart rate in Australian varanid lizards," Physiological Zoology, vol. 37, pp. 341-355, 1964.

[33] G. J. W. Webb, C. R. Johnson, and B. T. Firth, "Head-body temperature differences in lizards," Physiological Zoology, vol. 45, pp. 130-142, 1972.

[34] H. Heatwole, B. T. Firth, and G. J. W. Webb, "Panting thresholds of lizards-I. Some methodological and internal influences on the panting threshold of an agamid, Amphibolurus muricatus," Comparative Biochemistry and Physiology, vol. 46, no. 4 a, pp. 799-826, 1973.

[35] S. N. Trautwein, C. J. Gordon, and J. E. Heath, "Changes in brain and body temperature of the lizard, Sceloporus undulatus hyacinthinus during rest and exercise," Comparative Biochemistry and Physiology-A Physiology, vol. 80, no. 2, pp. 199-204, 1985.

[36] J. H. Zar, Biostatistical Analysis, Prentice Hall, Upper Saddle River, NJ, USA, 4th edition, 1999.

[37] C. Ciofi, J. Puswati, D. Winana, M. E. De Boer, G. Chelazzi, and P. Sastrawan, "Preliminary analysis of home range structure in the Komodo monitor, Varanus komodoensis," Copeia, no. 2, pp. 462-470, 2007.

[38] B. H. Brattstrom, "Rate of heat loss by large Australian monitor lizards," Bulletin Southern California Academy of Science, vol. 72, pp. 52-54, 1973. 
[39] R. B. Huey and E. R. Pianka, "Ecological consequences of foraging mode," Ecology, vol. 63, pp. 991-999, 1981.

[40] D. Y. Ayers and R. Shine, "Thermal influences on foraging ability: body size, posture and cooling rate of an ambush predator, the python Morelia spilota," Functional Ecology, vol. 11, no. 3, pp. 342-347, 1997.

[41] E. C. Crawford Jr., "Brain and body temperatures in a panting lizard," Science, vol. 177, no. 4047, pp. 431-433, 1972.

[42] W. R. Dawson and J. R. Templeton, "Physiological responses to temperature in the alligator lizard Gerrhonotus multicarinatus," Ecology, vol. 47, pp. 759-765, 1966.

[43] P. B. Frappell and C. B. Daniels, "Temperature effects on ventilation and metabolism in the lizard, Ctenophorus nuchalis," Respiration Physiology, vol. 86, no. 2, pp. 257-270, 1991.

[44] T. Owerkowicz, C. C. Farmer, J. W. Hicks, and E. L. Brainerd, "Contribution of gular pumping to lung ventilation in monitor lizards," Science, vol. 284, no. 5420, pp. 1661-1663, 1999.

[45] M. S. A. D. Al-Ghamdi, J. F. X. Jones, and E. W. Taylor, "Evidence of a functional role in lung inflation for the buccal pump in the agamid lizard Uromastyx aegyptius microlepis," Journal of Experimental Biology, vol. 204, no. 3, pp. 521-531, 2001.

[46] E. C. Crawford Jr. and B. J. Barber, "Effects of core, skin, and brain temperature on panting in the lizard Sauromalus obesus," American Journal of Physiology, vol. 226, no. 3, pp. 569-573, 1974.

[47] J. Vernon and H. Heatwole, "Temperature relations of the water skink, Sphenomorphus quoyi," Journal of Herpetology, vol. 4, pp. 141-153, 1970.

[48] G. J. Tattersall and R. M. Gerlach, "Hypoxia progressively lowers thermal gaping thresholds in bearded dragons, Pogona vitticeps," Journal of Experimental Biology, vol. 208, no. 17, pp. 3321-3330, 2005.

[49] E. C. Crawford Jr., J. Palomeque, and B. J. Barber, "A physiological basis for head-body temperature differences in a panting lizard," Comparative Biochemistry and PhysiologyPart A, vol. 56, no. 2, pp. 161-163, 1977.

[50] J. E. Heath, "Head-body temperature differences in horned lizards," Physiological Zoology, vol. 37, pp. 273-279, 1964.

[51] C. B. DeWitt, "Precision of thermoregulation and its relation to environmental factors in the desert iguana, Dipsosaurus dorsalis," Physiological Zoology, vol. 40, pp. 49-66, 1967.

[52] H. W. Campbell, "The effects of temperature on the auditory sensitivity of lizards," Physiological Zoology, vol. 42, pp. 183210, 1969.

[53] H. Heatwole, "Thermal ecology of the desert dragon Amphibolurus inermis," Ecological Monographs, vol. 40, pp. 425-457, 1970.

[54] G. J. W. Webb and H. Heatwole, "Patterns of heat distribution within the bodies of some Australian pythons," Copeia, pp. 209-220, 1971.

[55] C. R. Johnson, “Thermoregulation in pythons-II. Head-body temperature differences and thermal preferenda in australian pythons," Comparative Biochemistry and Physiology-Part A, vol. 45, no. 4, pp. 1064-1087, 1973.

[56] S. R. H. Davidson and D. F. James, "Measurement of thermal conductivity of bovine cortical bone," Medical Engineering and Physics, vol. 22, no. 10, pp. 741-747, 2000.

[57] O. I. Craciunescu, L. E. Howle, and S. T. Clegg, "Experimental evaluation of the thermal properties of two tissue equivalent phantom materials," International Journal of Hyperthermia, vol. 15, no. 6, pp. 509-518, 1999.
[58] M. E. Dorcas and C. R. Peterson, "Head-body temperature differences in free-ranging rubber boas," Journal of Herpetology, vol. 31, no. 1, pp. 87-93, 1997.

[59] J. E. Heath, "Venous shunts in the cephalic sinuses of horned lizards," Physiological Zoology, vol. 39, pp. 30-35, 1966.

[60] R. B. Huey and M. Slatkin, "Cost and benefits of lizard thermoregulation,” Quarterly Review of Biology, vol. 51, no. 3, pp. 363-384, 1976.

[61] K. A. Hammond, J. R. Spotila, and E. A. Standora, "Basking behavior of the turtle Pseudemys scripta: effects of digestive state, acclimation temperature, sex and season," Physiological Zoology, vol. 61, pp. 69-77, 1988.

[62] L. M. Carrascal, P. Lopex, J. Martin, and A. Salvador, "Basking and antipredator behavior in a high altitude lizard: implications of heat-exchange rate," Ethology, vol. 92, pp. 143154, 1992. 

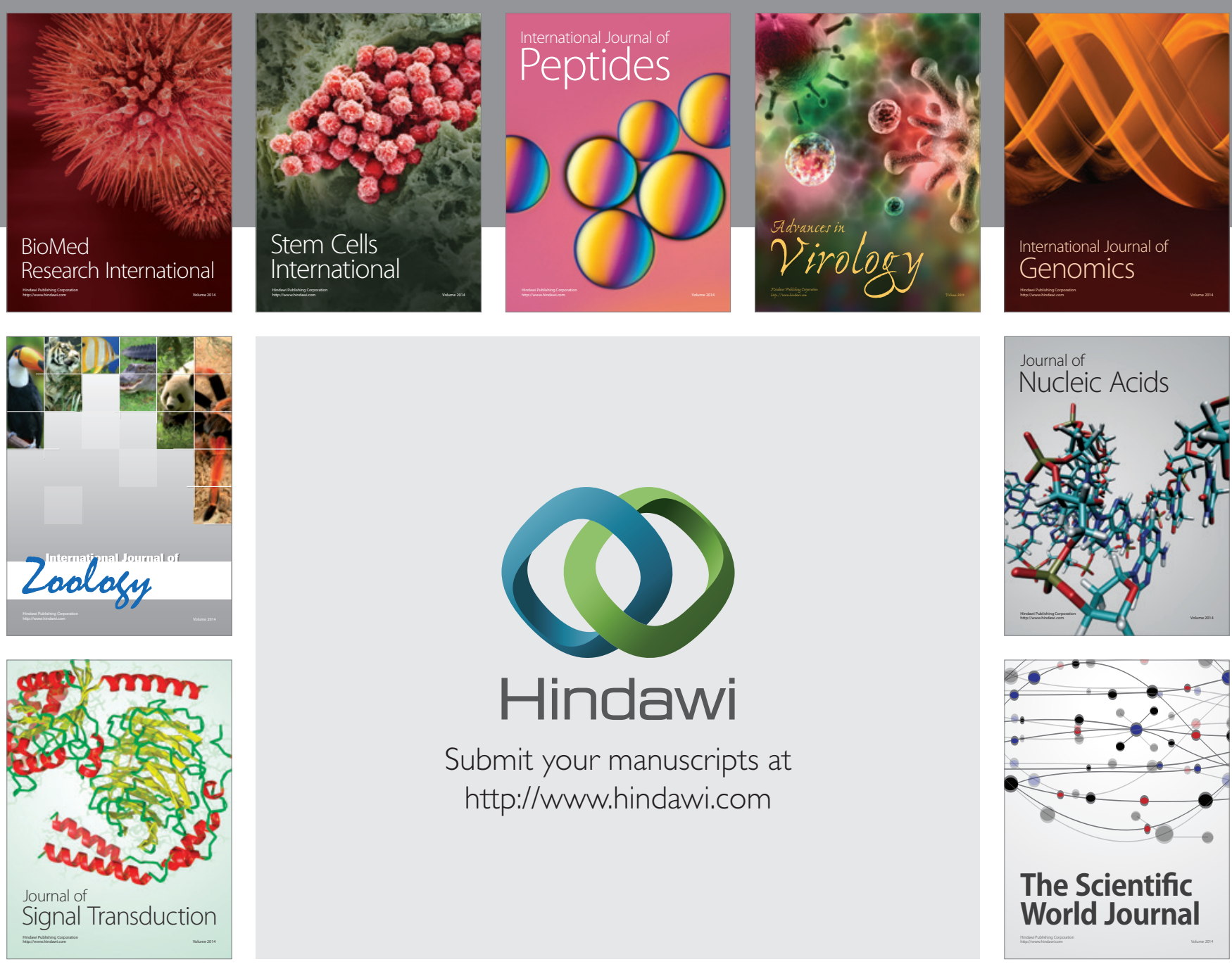

Submit your manuscripts at

http://www.hindawi.com
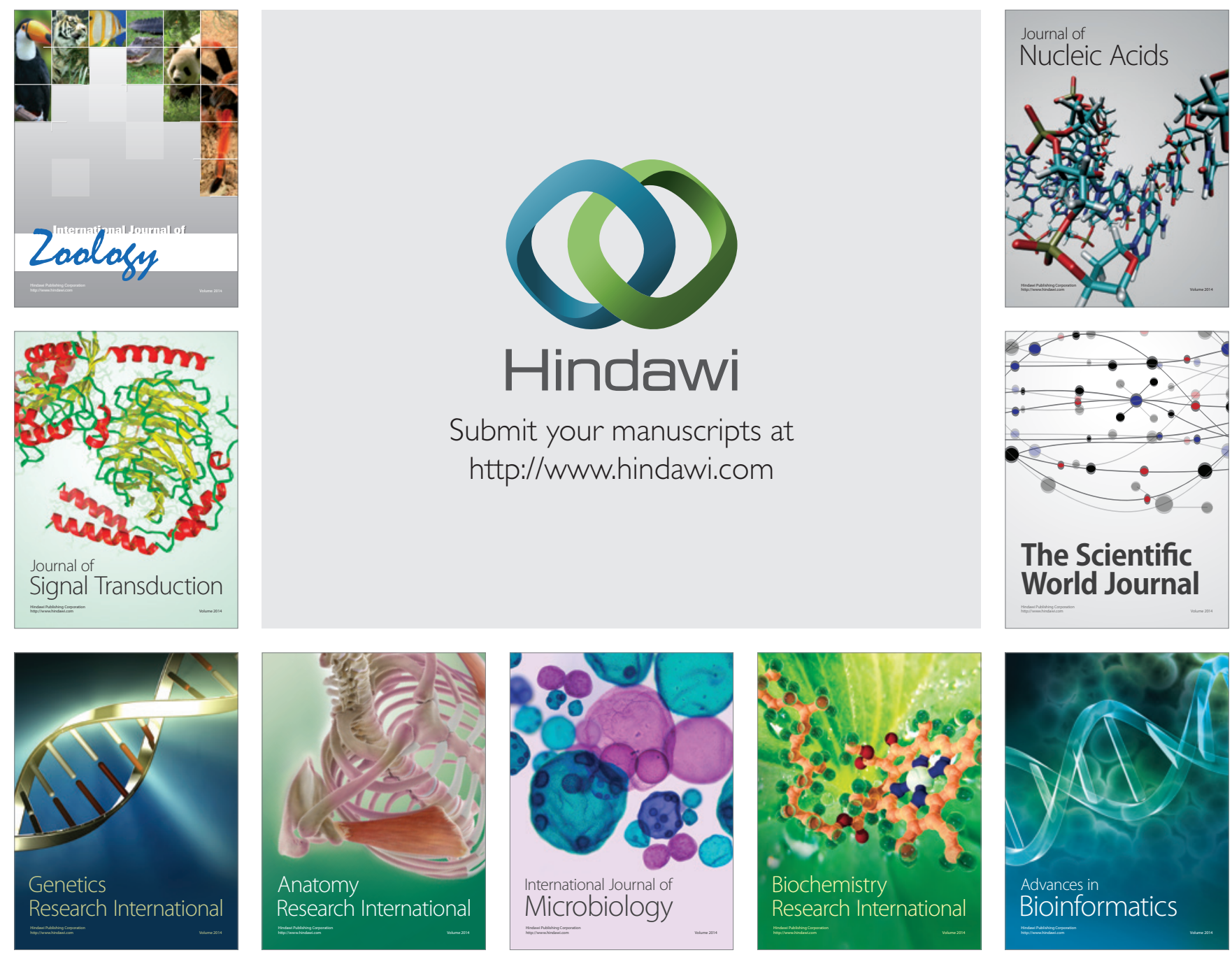

The Scientific World Journal
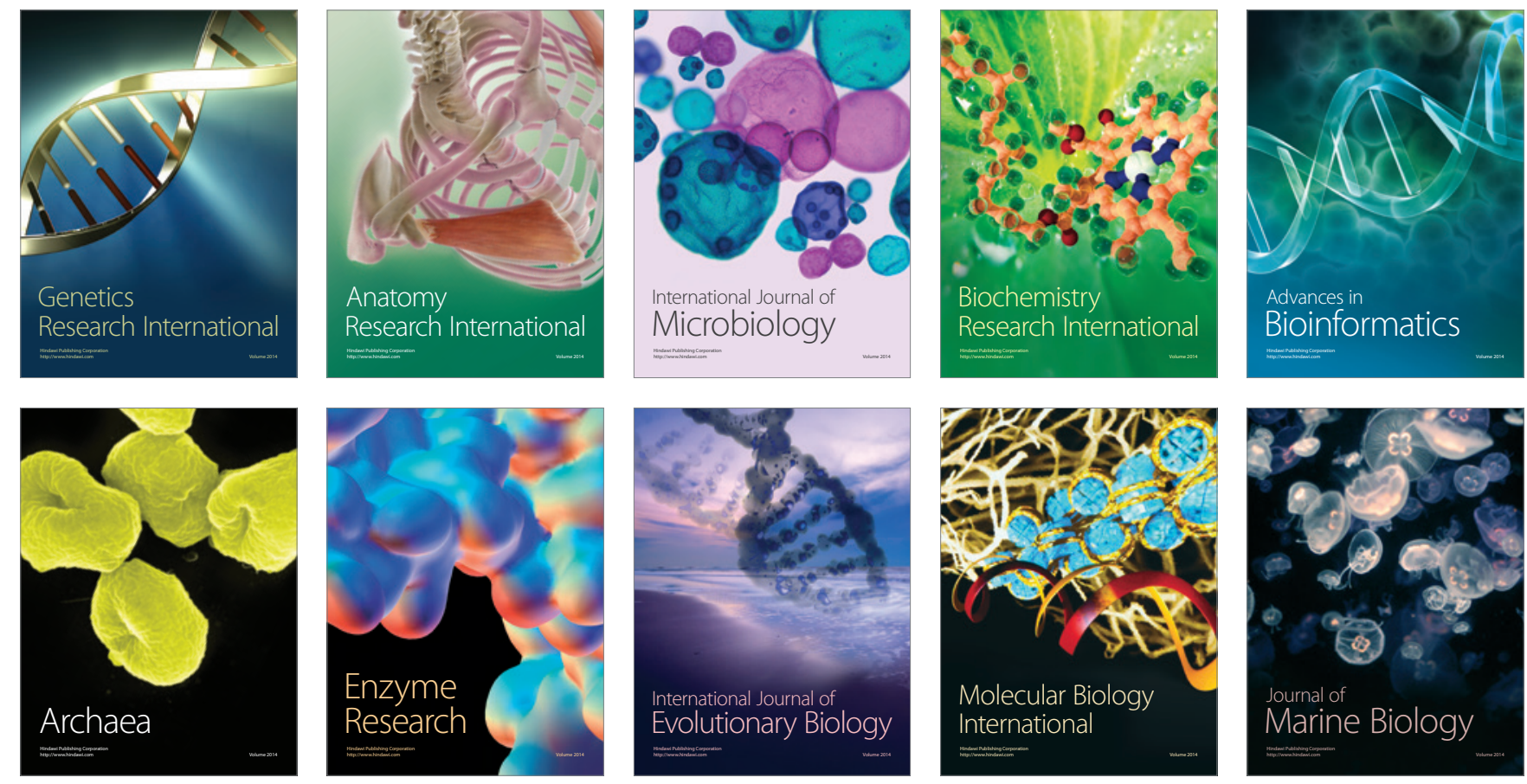